\title{
Co-occurrence or dependence? Using spatial analyses to explore the interaction between palms and Rhodnius triatomines
}

\author{
Johan M. Calderón * (10 and Camila González
}

\begin{abstract}
Background: Triatomine bugs are responsible for the vectorial transmission of the parasite Trypanosoma cruzi, the etiological agent of Chagas disease, a zoonosis affecting 10 million people and with 25 million at risk of infection. Triatomines are associated with particular habitats that offer shelter and food. Several triatomine species of the genus Rhodnius have a close association with palm crowns, where bugs can obtain microclimatic stability and blood from the associated fauna. The Rhodnius-palm interaction has been reported in several places of Central and South America. However, the association in the distributions of Rhodnius species and palms has not been explicitly determined.
\end{abstract}

Methods: Niches of Rhodnius and palm species with reports of Rhodnius spp. infestation were estimated by minimum volume ellipsoids and compared in the environmental and the geographical space to identify niche similarity. Rhodnius spp. niche models were run with the palm distributions as environmental variables to determine if palm presence could be considered a predictor of Rhodnius spp. distributions, improving model performance.

Results: Niche similarity was found between all the studied Rhodnius and palm species showing variation in niche overlap among the involved species. Most of the areas with suitable conditions for Rhodnius species were also suitable to palm species, being favorable for more than one palm species in the majority of locations. Performance was similar in Rhodnius niche models with and without palm distributions. However, when palm distributions were included, their contribution to the model was high, being the most important variable in some Rhodnius spp.

Conclusions: To our knowledge, this is the first time that the distributions of Rhodnius and palm species were compared on a large scale and their spatial association explicitly studied. We found spatial association between Rhodnius and palm species can be explained because both organisms shared environmental requirements, and most of the areas with suitable conditions for Rhodnius species were also suitable to several palm species. Rhodnius presence would not be restricted to palm presence but the zones with palm presence could be more suitable for Rhodnius spp. presence.

Keywords: Triatomines, Rhodnius-infested palms, Ecological niche modeling, Niche similarity, Unlinked biotic predictors

*Correspondence: jm.calderon@uniandes.edu.co

Centro de Investigaciones en Microbiología y Parasitología Tropical, (CIMPAT), Departamento de Ciencias Biológicas, Universidad de Los Andes, Bogotá D.C., Colombia

\begin{abstract}
Background
Triatomine bugs are responsible for the vectorial transmission of the parasite Trypanosoma cruzi, the etiological agent of Chagas disease, a zoonosis affecting 10 million people and with 25 million at risk of infection [1]. Triatomines show associations with particular habitats that offer shelter and food [2]; this association can be specific
\end{abstract}

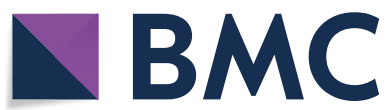

(c) The Author(s) 2020. This article is licensed under a Creative Commons Attribution 4.0 International License, which permits use, sharing, adaptation, distribution and reproduction in any medium or format, as long as you give appropriate credit to the original author(s) and the source, provide a link to the Creative Commons licence, and indicate if changes were made. The images or other third party material in this article are included in the article's Creative Commons licence, unless indicated otherwise in a credit line to the material. If material is not included in the article's Creative Commons licence and your intended use is not permitted by statutory regulation or exceeds the permitted use, you will need to obtain permission directly from the copyright holder. To view a copy of this licence, visit http://creativeco mmons.org/licenses/by/4.0/. The Creative Commons Public Domain Dedication waiver (http://creativecommons.org/publicdomain/ zero/1.0/) applies to the data made available in this article, unless otherwise stated in a credit line to the data. 
to one type of habitat, as occurs with Psammolestes triatomines living in bird nests, or to several habitats such as Triatoma sordida, which can be found in rock piles, hollow trees and human dwellings [3]. Several species belonging to the genus Rhodnius have been found in close association with palms in their sylvatic cycle [4], some related to a particular type of palm such as Rhodnius brethesi to Leopoldinia piassaba palms, and others, such as $R$. robustus, associated with several palm species [5]. Palm crowns have been suggested as suitable habitats for Rhodnius bugs due to their inner microclimatic stability and food availability. Microclimatic stability of the palm is likely to be the result of leaf insertion, creating a highly protected environment with a stable temperature and humidity [6], while blood sources for the Rhodnius bugs, are provided by the fauna visiting or inhabiting the palm [6]. The fact that palms are inhabited by Chagas disease vectors is important from a public health perspective, since insects living in palms can infest nearby houses [7]. The migration of Rhodnius vectors from palms to households could threaten vector control programs conducted during Chagas disease control initiatives, since re-infestation of insecticide-treated dwellings can occur [8].

In the Americas, palms are distributed from southern USA to northern Argentina and central Chile [9]. From 550 palm species naturally occurring in the Americas, 19 have been reported to be infested by Rhodnius bugs (Additional file 1: Table S1). Rhodnius species are distributed from Central America to Bolivia, with the Amazon region the zone showing the greatest number of species [10]. Some Rhodnius species, such as $R$. pictipes and $R$. robustus, have very wide geographical distributions including several countries; while others, such as R. ecuadoriensis and $R$. colombiensis, are restricted to certain regions inside one or two countries [11]. Palms infested by Rhodnius bugs have been observed and reported in numerous areas in Central and South America [5] suggesting that sylvatic Rhodnius spp. distributions broadly coincide with palm distributions [2]. However, the role of palm presence as a determinant variable on Rhodnius spp. distributions has not been explicitly assessed.

Under normal reproduction and dispersal conditions, a species is predicted to be present in a geographical region that is directly congruent with the distribution of its Grinnellian niche [12]. This niche interpretation focuses on conditions necessary for the species' existence, and it has been extensively used in studies of niche estimation and species distribution analyses [13, 14]. Rhodnius and palm species would occupy similar geographical regions if their Grinnellian niches were similar. Moreover, the locations with suitable conditions for both Rhodnius and palm species could be considered as potential zones of Rhodnius-palm co-occurrence.
The aim of this study was to determine if there is a close spatial and ecological association on a broad scale, between Rhodnius spp. and Rhodnius-infested palms, suggesting habitat dependence. To do so, the similarity between Grinnellian niches of Rhodnius spp. and infested palm species was determined in both the environmental and the geographical space. Additionally, the role of palm presence as an important predictor of Rhodnius spp. distributions was evaluated through the use of ecological niche models (ENMs).

\section{Methods}

\section{Database assemblage}

Species occurrences (i.e. geographical coordinates from where the species had been collected) were obtained for Rhodnius species (1980-2000) from "DataTri" [15], and for palms from the Global Biodiversity Information Facility (GBIF) (1980-2000), downloaded in October 2018 using the "gbif" function of the dismo R package [16] (Rhodnius and palm species are listed in Additional file 1: Table S1). Rhodnius spp. occurrences in "DataTri" include records from domestic, peridomestic and sylvatic habitats; however not all records have this information, therefore origin could not be used as a filter [15]. The databases were depurated by choosing only georeferenced occurrences, removing duplicated records, and validated with known geographical distributions reported in the literature [17-20]. Also, occurrences in elevations outside species limits were omitted for both Rhodnius spp. and palms [9, 11, 17]. Rhodnius prolixus occurrences in Central America were excluded from the study since they have never been associated with palms [21], and $R$. prolixus are no longer found in previously reported areas of Central America as a possible consequence of vector control initiatives.

To reduce the effect of sampling bias in the occurrence dataset, spatial thinning was performed with the spThin R package [22] using a minimum nearest neighbor distance greater than or equal to $10 \mathrm{~km}$. This distance was chosen based on the high spatial heterogeneity, and the same distance has been used in previous studies on highly heterogeneous areas [23, 24]. Moreover, this distance is much larger than the flight dispersal reported for some Rhodnius species (e.g. c. $200 \mathrm{~m}$ for R. prolixus) [25], avoiding the use of many occurrences from closely located populations.

\section{Niche estimation and comparison}

To identify niche similarity between Rhodnius and palms species, their Grinnellian niches were estimated and compared in the environmental and geographical space. For this purpose, an initial set of environmental variables was composed including the 19 bioclimatic 
variables from WorldClim [26], and 42 variables with remote sensing information of land surface temperature (LST), normalized difference vegetation index (NDVI) and middle infrared radiation (MIR). The remote sensing variables were calculated from AVHRR (advanced very high-resolution radiometer) images and processed by the TALA group (Oxford University, UK) using the temporal decomposition of Fourier [27]. Pearson's correlation coefficient was calculated among environmental variables to avoid collinearity, and when a group of variables with high correlation was found (i.e. absolute $r$-value > $0.7)$, only one variable was selected. This selection was based on which variable grouped more temporal information (e.g. yearly over monthly). The final nine selected environmental variables were five bioclimatic variables (BIO 1, annual mean temperature; BIO 2, mean diurnal range; $\mathrm{BIO} 12$, annual precipitation; $\mathrm{BIO} 15$, precipitation seasonality; and BIO 18, precipitation of warmest quarter), and four remote sensing variables (mean LST, LST annual phase, mean NDVI, and NDVI annual phase). Correlation was double-checked by the variable inflation factor, obtaining values lower than three for each variable. The spatial resolution of all the environmental layers was $2.5^{\circ}\left(\sim 8 \mathrm{~km}^{2}\right)$.

Only Rhodnius and palm species with more than 90 occurrences were considered for niche analyses. This threshold was determined by the number of environmental variables used, following the suggestion of Guisan et al. [28] of at least 10 records per environmental variable.

Grinnellian niches were estimated as minimum-volume ellipsoids (MVE) in the environmental space using the NicheA software v. 3.0 [29]. As background data, the three first PCAs from the nine environmental variables were obtained ( $72 \%$ of total variation). The background extent included the continental Neotropics from southern Nicaragua to Bolivia [15], the area corresponding to Rhodnius spp. distributional range including five degrees below and above the latitudinal known limits. Overlaps between each Rhodnius and palm species MVEs were estimated using NicheA (with a default precision of 0.01). Along with the niches of Rhodnius and palm species, we estimated a niche for the genus Rhodnius and another considering all the infested palms studied here. The Rhodnius niche was estimated with occurrences of all Rhodnius species, and the infested palms niche with the occurrences of all palm species infested by any Rhodnius species (species in Additional file 1: Table S1). To allow comparisons between Rhodnius species, niche overlaps were normalized by the Rhodnius species niche volume (= (Niche overlap volume/MVEs volume of the Rhodnius species) $\times 100$ ).
Palms and Rhodnius MVEs were projected and compared on the geographical space and used to estimate the potential areas of Rhodnius spp. and palm co-occurrence. For each Rhodnius and palm species, $80 \%$ of the occurrences located within the MVEs were randomly drawn using the "probability" method (NicheA converted the probability according to a logistic function of threshold $\beta=0.7$ and slope $\alpha=-0.05$, and sampled based on the converted probability. The areas with high probability contain more occurrences). With those occurrences, ENMs were obtained using the maximum entropy algorithm (MaxEnt v. 3.4.1) [30] (with 10,000 background points, 500 iterations, regularization coefficient $=1$, linear, quadratic and product feature classes, and log-log output). Binary maps were obtained using the $10 \%$ error threshold, and the areas where estimated Rhodnius spp. and palms niches overlapped were considered as potential areas for Rhodnius-palm co-occurrence. Niches comparisons were carried out inside the geographical range of each Rhodnius species including five degrees far from the known geographical limits.

\section{Palm distributions as predictors of Rhodnius ENMs}

To determine if palm presence could be considered a predictor of Rhodnius species distributions, Rhodnius models were run twice: first with only environmental variables (the same nine variables used in the niche estimation), and again including palm distributions as environmental variables (the nine environmental variables plus seven palm niche distributions). Palm distribution could be considered an appropriate predictor for ENMs because it is a variable not affected by the presence of a Rhodnius species (i.e. unlinked variable) [31]. For representation of the niche, unlinked environmental variables are preferred [32], because linked variables (i.e. affected by the focal species) can increase the complexity of the niche representation due to possible feedbacks between variables [31]. Palm potential distributions used here were the palm niche geographical projections (continuous outputs) obtained from the previous section.

ENMs were run for each Rhodnius species and the calibration area was the species geographical range including five degrees below and above the known limits. Maximum entropy (MaxEnt v. 3.4.1) was used as modeling algorithm (with 10,000 background points 500 iterations, and log-log output). Several regularization coefficients $(0.02,0.1,0.46,1,2.2$ and 4.6) and feature classes (linear, quadratic and product) were tested for each species with the ENMeval R package [33], and the options giving the lowest corrected Akaike information criterion (AICc) were selected (Additional file 1: Table S2). For each species, ENMs were run ten times with different presence samples to test robustness [28], and model 
evaluation was performed each time. In each repetition, $80 \%$ of the occurrences were randomly chosen for training the model and the remaining $20 \%$ of the occurrences used for testing. Two evaluation methods were carried out: partial area under the ROC curve (pAUC) [34] and omission rates [14]. The pAUC with an error of 0.10 and its ratio to the AUC null model were calculated for each repetition (performed with NicheA). Ten-percentile and zero-percentile training omission rates (proportion of testing occurrences omitted with each threshold) were calculated along with their predicted presence area (performed with MaxEnt). Evaluation statistics were compared between Rhodnius ENMs with and without palm distributions using a paired t-test $(\alpha=0.05)$. To this purpose, the same training and test datasets were used in both cases.

The final continuous map for each Rhodnius species was the mean of the ten obtained outputs (from the repetitions), and the uncertainty map was the standard deviation of those outputs. The continuous map was transformed to a binary map using the mean of the tenpercentile thresholds of the outputs.

\section{Results}

\section{Database assemblage}

Inside the background area, we obtained 1930 records of Rhodnius species and 5412 records of Rhodnius-infested palm species. After depuration and spatial thinning, the final dataset consisted of 930 records of Rhodnius species and 1757 of infested palms. Four Rhodnius species were selected, which had more than 90 occurrences: $R$. neglectus, $R$. pictipes, $R$. prolixus and $R$. robustus. By the same criteria, seven palm species were selected: Acrocomia aculeata, Astrocaryum aculeatum, Attalea butyracea, Attalea maripa, Attalea phalerata, Mauritia flexuosa and Oenocarpus bataua (Fig. 1, Table 1).

\section{Niche estimation and comparison}

Niche overlap between the genus Rhodnius and infested palms represented $93.48 \%$ of the Rhodnius niche but only $57.38 \%$ of the infested palms niche (Fig 2a). The entire niches of $R$. neglectus and $R$. pictipes and almost all the niche volume of $R$. prolixus and $R$. robustus fell inside the niche of infested palms (Table 2).

Table 1 Rhodnius and palm occurrences

\begin{tabular}{llll}
\hline Organism & Species & Initial dataset & Final dataset $^{\text {a }}$ \\
\hline Rhodnius & R. neglectus & 143 & 102 \\
& R. pictipes & 166 & 130 \\
& R. prolixus & 1215 & 352 \\
& R. robustus & 116 & 96 \\
Palms & Ac. aculeata & 395 & 157 \\
& As. aculeatum & 256 & 120 \\
& A. butyracea & 307 & 155 \\
& A. maripa & 292 & 160 \\
& A. phalerata & 329 & 150 \\
& M. flexuosa & 306 & 326 \\
& O. bataua & 724 &
\end{tabular}

a Data set obtained after data depuration and spatial thinning
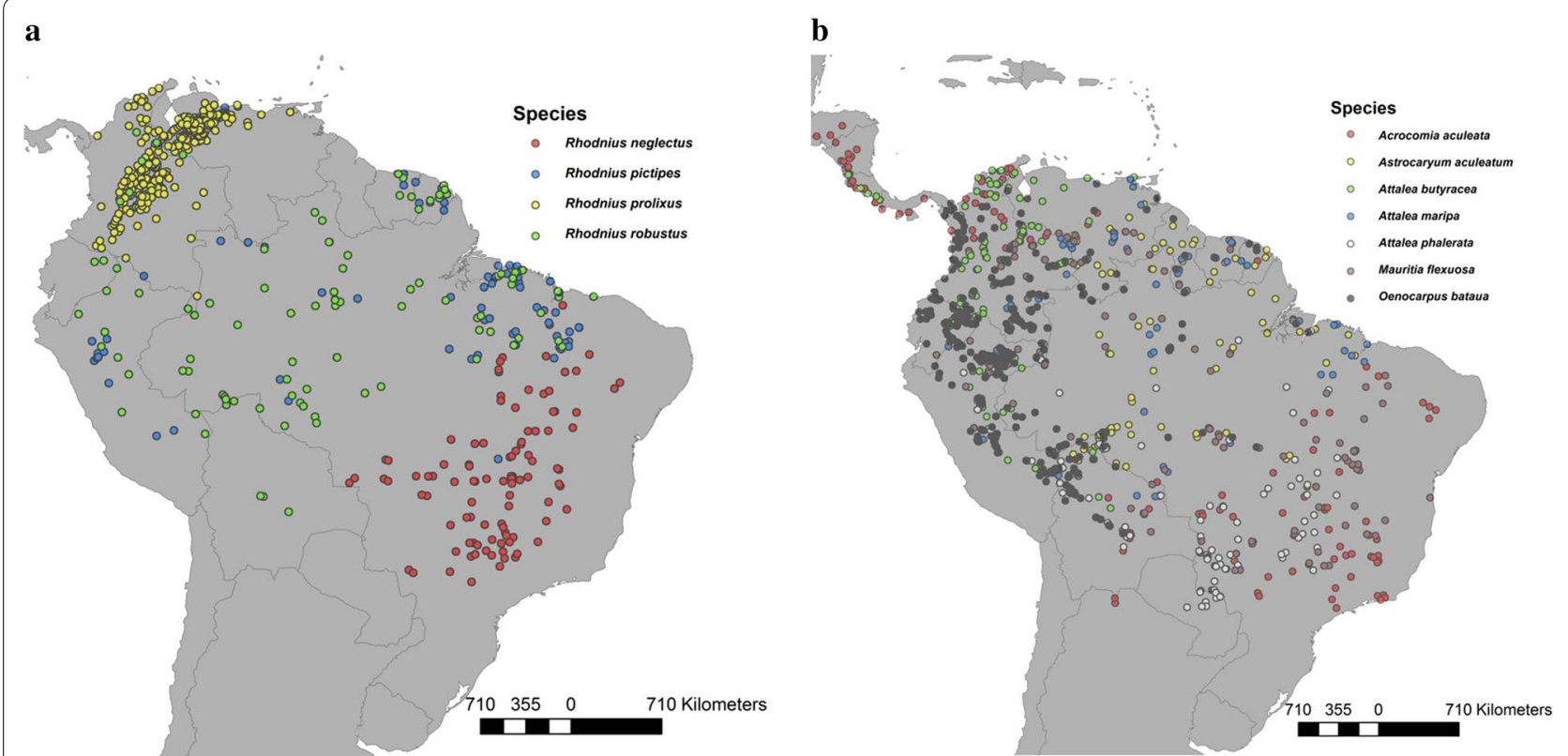

Fig. 1 a Final set of Rhodnius occurrences. b Final set of infested palm occurrences. Maps elaborated with ArcGis 10.4.1. Occurrences data obtained from DataTri [15] and GBIF 


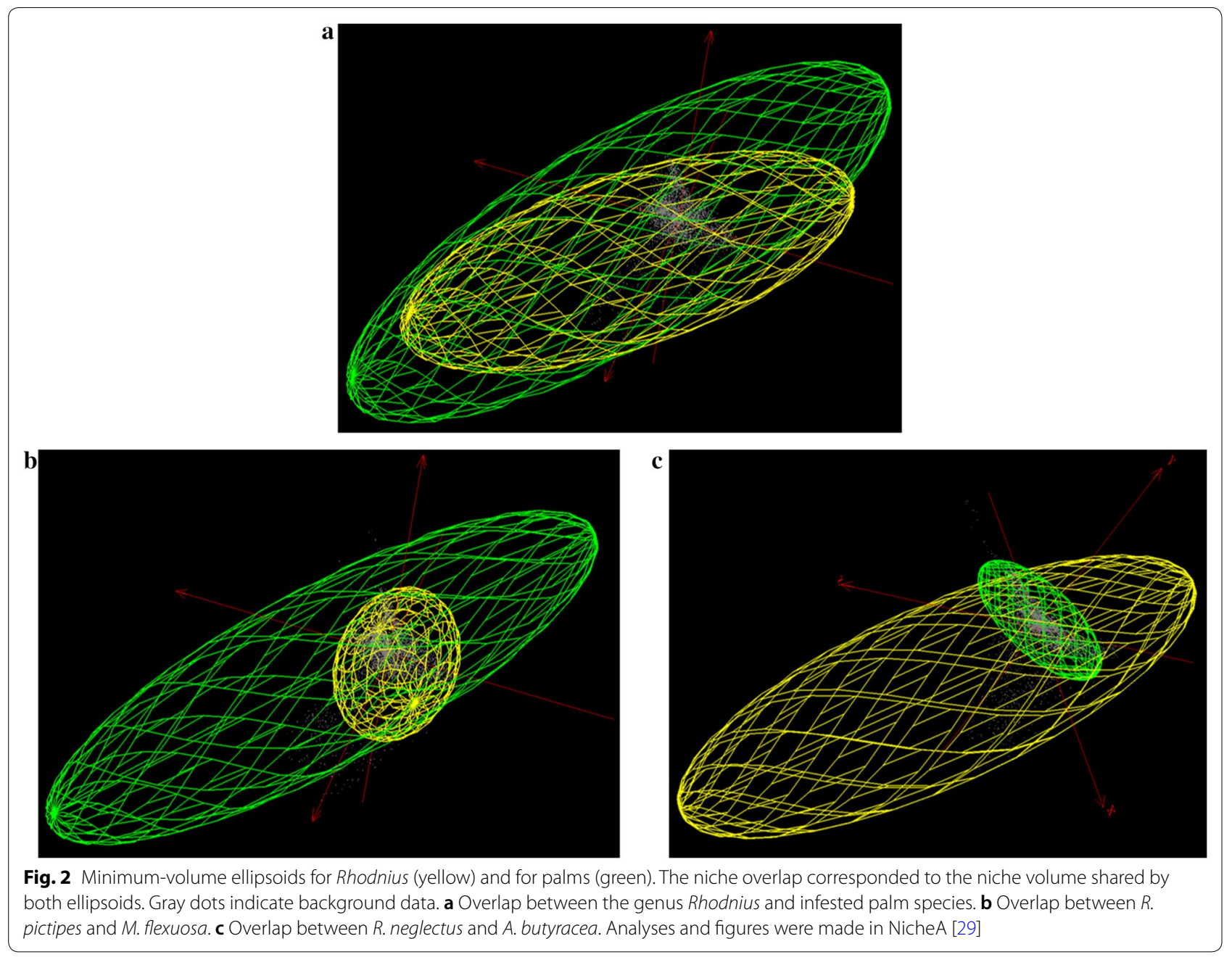

When analyzed by species, niche volumes showed great variation; for example, the niche of $R$. neglectus was

Table 2 Percentage of Rhodnius niche volume shared with palm species

\begin{tabular}{lllll}
\hline $\begin{array}{l}\text { Species (niche } \\
\text { volume) }\end{array}$ & $\begin{array}{l}\text { R. neglectus } \\
(873)\end{array}$ & $\begin{array}{l}\text { R. pictipes } \\
(201)\end{array}$ & $\begin{array}{l}\text { R. prolixus } \\
(113)\end{array}$ & $\begin{array}{l}\text { R. robustus } \\
(143)\end{array}$ \\
\hline Infested palms (2098) & 100 & 100 & 91.15 & 96.50 \\
Ac. aculeata (254) & $\mathbf{2 5 . 6 0}$ & $\mathbf{7 6 . 6 3}$ & 59.86 & $\mathbf{7 7 . 5 6}$ \\
As. aculeatum (500) & 33.98 & 92.49 & 75.33 & $\mathbf{8 7 . 3 1}$ \\
A. butyracea (96) & 8.80 & 40.33 & $\mathbf{5 2 . 6 0}$ & $\mathbf{5 6 . 3 8}$ \\
A. maripa (182) & 13.57 & $\mathbf{6 5 . 9 8}$ & $\mathbf{6 4 . 4 6}$ & $\mathbf{7 9 . 3 8}$ \\
A. phalerata (239) & $\mathbf{2 5 . 7 7}$ & $\mathbf{7 4 . 4 9}$ & 48.63 & $\mathbf{7 3 . 3 5}$ \\
M. flexuosa (1624) & $\mathbf{9 2 . 7 7}$ & 95.47 & 81.70 & 90.53 \\
O. bataua (191) & 13.41 & $\mathbf{6 7 . 2 8}$ & $\mathbf{7 3 . 4 7}$ & $\mathbf{8 7 . 0 3}$ \\
\hline
\end{tabular}

Notes: Niche overlaps were normalized by each Rhodnius species niche volume. Niche overlap in bold are for infestations reported in the literature (see Additional file 1: Table S1) more than 7 times greater than the niche of $R$. prolixus, and the niche of $M$. flexuosa was more than 17 times greater than the niche of $A$. butyracea (Table 2). Niche overlap was found among all the Rhodnius and palm species compared; however, in each Rhodnius species, the proportion of niche overlap varied notably among palm species (Table 2). The maximum niche overlap was found between $R$. pictipes and M. flexuosa (95.47\% of the niche of $R$. pictipes; Fig. $2 \mathrm{~b})$, while the minimum overlap was found between $R$. neglectus and A. butyracea ( $8.8 \%$ of the niche of $R$. neglectus; Fig 2c).

Considering palms, all of the species overlapped most of their niche volume with the genus Rhodnius niche (Table 3). Attalea phalerata and Ac. aculeata were the palm species sharing the highest proportions of their niches, while $M$. flexuosa was the one sharing the lowest proportion. 
Table 3 Percentage of palms niches shared with species of the genus Rhodnius

\begin{tabular}{ll}
\hline Species (niche volume) & $\begin{array}{l}\text { Rhodnius } \\
(1289)\end{array}$ \\
\hline Ac. aculeata (254) & 92.12 \\
As. aculeatum (500) & 75.00 \\
A. butyracea (96) & 88.54 \\
A. maripa (182) & 79.67 \\
A. phalerata (239) & 94.14 \\
M. flexuosa (1624) & 62.19 \\
O. bataua (191) & 78.53 \\
\hline
\end{tabular}

Notes: Niche overlaps were normalized by each palm species niche volume

Table 4 Percentage of palm suitable areas inside the Rhodnius spp. presence areas

\begin{tabular}{lllll}
\hline No. of palm species & R. neglectus & R.pictipes & R.prolixus & R.robustus \\
\hline 0 & 18.78 & 7.46 & 22.52 & 4.57 \\
1 & 43.34 & 19.44 & 8.44 & 13.27 \\
2 & 17.56 & 21.91 & 24.55 & 19.43 \\
3 or more & 20.32 & 51.20 & 44.49 & 62.73 \\
\hline
\end{tabular}

Notes: Palm areas are discriminated by the number of palm species that could be present
When palms and Rhodnius MVEs were projected and compared in geographical space, we found zones with suitable conditions for at least one infested palm species (from the selected palms) inside the Rhodnius species predicted distributions; these zones covered at least $75 \%$ of the Rhodnius presence area (Table 4, Figs. 3 and 4). For $R$. pictipes, $R$. prolixus and $R$. robustus distributions, a great proportion of the presence area was suitable for three or more palm species (Table 4, Figs. 3 and 4). In those Rhodnius species, a small proportion of the presence area was suitable to only one palm species.

Almost all Rhodnius and palm species had areas of potential co-occurrence; nevertheless, inside each Rhodnius presence area the proportion of palm co-occurrence was highly variable among palm species (Table 5), corresponding with the results of niche overlap. Each Rhodnius species shared a high proportion of suitable areas with certain palm species, but a very low proportion with others (e.g. wide sharing of $R$. prolixus with $A$. butyracea but very small with $A$. phalerata). Considering palm species, the only palm sharing a high proportion of suitable areas with all the Rhodnius species was M. flexuosa (Table 5). For the remaining palms, the area of co-occurrence with at least one Rhodnius species was very small (less than 0.05 ).

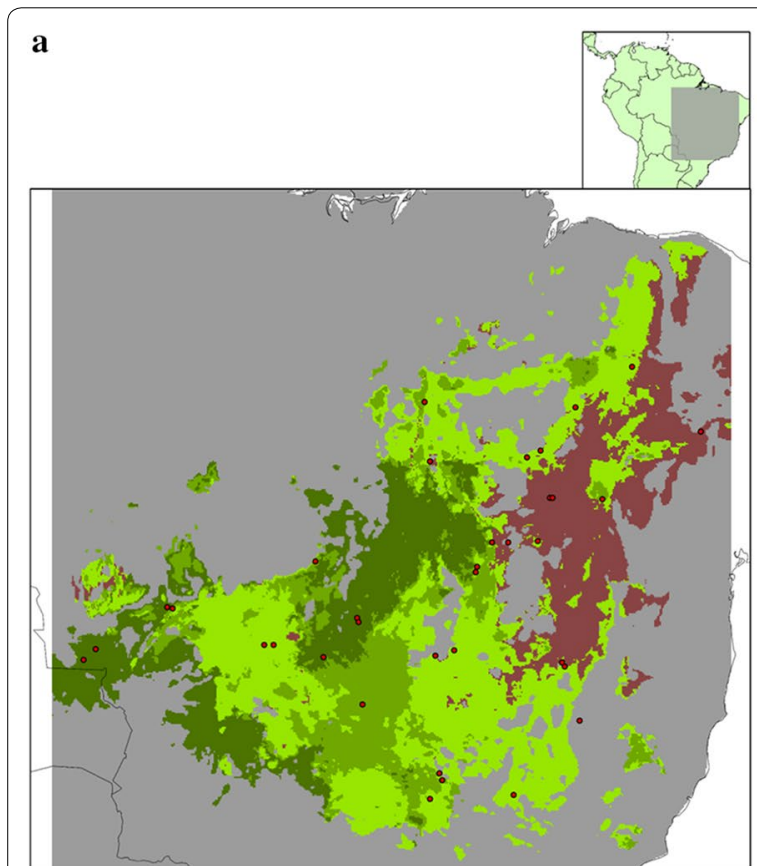

b

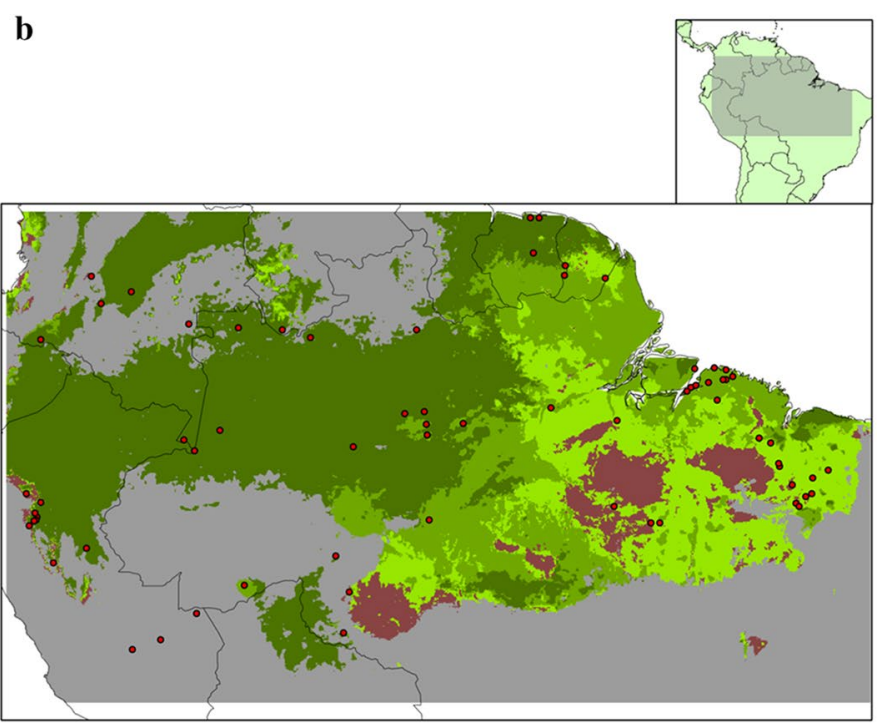

Fig. 3 Suitable areas for palms inside the potential distributions of Rhodnius neglectus (a) and Rhodnius pictipes (b). Red points indicate Rhodnius species occurrences inside MVEs. Grey indicates unsuitable habitats for the Rhodnius species. Green and brown indicates suitable habitats for the Rhodnius species (light green, suitable habitats for only one palm species; intermediate green, suitable for two palm species; dark green, suitable for three or more palm species; brown, not suitable for any of the palm species modeled). Geographical extensions were based on the area covered by the occurrences. Presence area was based on a 10\% training omission rate. Maps were constructed with ArcGIS 10.4 

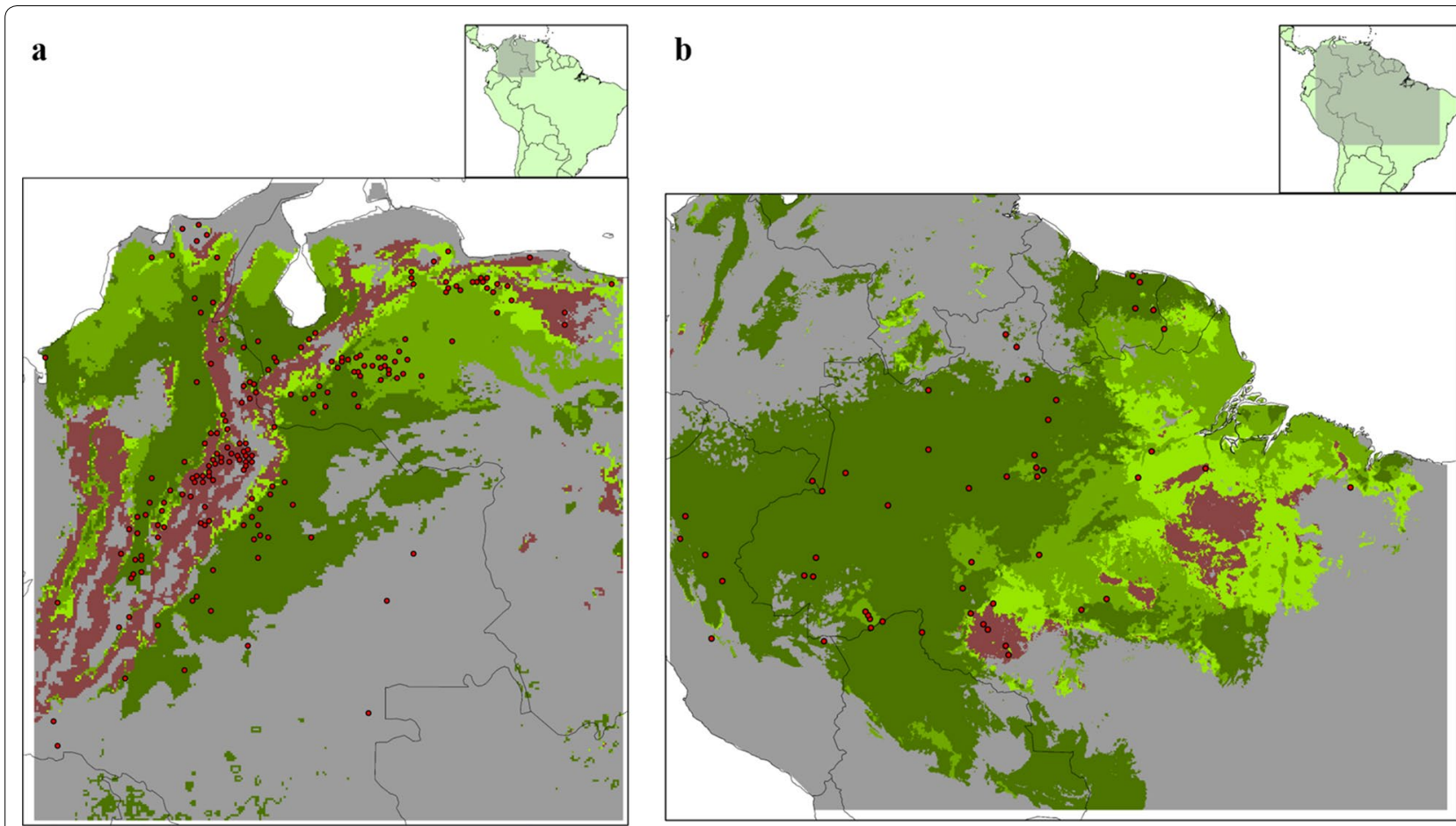

Fig. 4 Suitable areas for palms inside the potential distributions of $\mathbf{a}$ Rhodnius prolixus and $\mathbf{b}$ Rhodnius robustus. Red points indicate Rhodnius species occurrences inside MVEs. Grey indicates unsuitable habitats for the Rhodnius species. Green and brown indicates suitable habitats for the Rhodnius species (light green, suitable habitats for only one palm species; intermediate green, suitable for two palm species; dark green, suitable for three or more palm species; brown, not suitable for any of the palm species modeled). Geographical extensions were based on the area covered by the occurrences. Presence area was based on a 10\% training omission rate. Maps were constructed with ArcGIS 10.4

Table 5 Percentage of Rhodnius spp. suitable areas shared with each palm species

\begin{tabular}{lllll}
\hline Species & R. neglectus & R. pictipes & R. prolixus & R. robustus \\
\hline Ac. aculeata & $\mathbf{6 5 . 6 6}$ & $\mathbf{4 . 3 9}$ & 57.38 & $\mathbf{9 . 7 2}$ \\
As. aculeatum & 2.24 & 55.91 & 9.51 & $\mathbf{5 7 . 8 0}$ \\
A. butyracea & 0 & 31.14 & $\mathbf{6 7 . 3 1}$ & $\mathbf{2 6 . 7 5}$ \\
A. maripa & 0 & $\mathbf{5 2 . 9 9}$ & $\mathbf{2 6 . 9 1}$ & $\mathbf{4 2 . 1 8}$ \\
A. phalerata & $\mathbf{3 4 . 0 8}$ & 20.25 & 0.07 & 38.37 \\
M. flexuosa & $\mathbf{3 9 . 2 0}$ & 71.82 & 44.23 & 72.47 \\
O. bataua & 0 & $\mathbf{4 2 . 8 2}$ & $\mathbf{4 5 . 4 4}$ & $\mathbf{3 7 . 9 1}$ \\
\hline
\end{tabular}

Notes: Proportions in bold font are for Rhodnius-palm interactions reported in the literature (see Additional file 1:Table S1)

\section{Palm distributions as predictors in Rhodnius ENMs}

For all the Rhodnius species, ENMs run with and without palm distributions had pAUC ratios higher than the null model line (i.e. pAUC ratios $>1$ ) (Table 6). In $R$. neglectus and $R$. robustus, pAUC ratios were significantly lower in models with palm distributions, while in $R$. pictipes and $R$. prolixus, pAUC ratios were higher in models with palms but the differences were not significant. Both omission rates $(10 \%$ and $0 \%)$ were similar in all the model comparisons except in $R$. prolixus where a $0 \%$ omission rate was significantly higher in ENMs with palms (Table 7 ). In $R$. neglectus, $R$. pictipes and $R$. prolixus, the $0 \%$ omission presence area reduced significantly in ENMs with palms, covering less area of predicted presence with a similar omission rate. However, this pattern was not observed in $10 \%$ omission rate presence areas.

Most of the Rhodnius models predicted an area of distribution adjusted to the occurrence points. No differences were observed between predictions of models with and without palms; small differences were mostly concentrated in the borders of the presence areas showing no clear pattern (Additional file 1: Figures S1S4). Prediction uncertainty was similar in both types of models (with and without palms) (Additional file 1: Figures S1-S3) except in $R$. robustus, where it slightly increased in models with palms in several zones of the distribution (Additional file 1: Figure S4).

Finally, palm distributions showed to be a relevant predictor for the Rhodnius ENMs (Table 8). In $R$. neglectus, $R$. prolixus and $R$. robustus, more than one palm species showed high contributions to the models, with Ac. aculeata distribution a common important 
Table 6 Partial AUC with $E=0.10$ for the Rhodnius ecological niche models with and without palm distributions

\begin{tabular}{llllll}
\hline Statistic & Palms included & R. neglectus & R.pictipes & R.prolixus & R. robustus \\
\hline pAUC value & No & $0.762 \pm 0.013$ & $0.445 \pm 0.046$ & $0.772 \pm 0.016$ & $0.559 \pm 0.035$ \\
& Yes & $0.718 \pm 0.015$ & $0.462 \pm 0.037$ & $0.786 \pm 0.014$ & $0.521 \pm 0.030$ \\
pAUC ratio & No & $1.609 \pm 0.018$ & $1.269 \pm 0.043$ & $1.614 \pm 0.023$ & $1.383 \pm 0.034$ \\
& Yes & $1.553 \pm 0.019^{*}$ & $1.288 \pm 0.034$ & $1.636 \pm 0.021$ & $1.301 \pm 0.047^{*}$
\end{tabular}

*Significant difference between models with and without palms (paired $t$-test, significance level $=0.05$ )

Notes: All values correspond to mean \pm standard error (based on 10 repetitions)

Table 7 Omission rates 10\% and 0\% for Rhodnius ecological niche models with and without palm distributions

\begin{tabular}{llllll}
\hline Statistic & Palms included & R. neglectus & R. pictipes & R. prolixus & R. robustus \\
\hline OR10\% & No & $0.124 \pm 0.020$ & $0.152 \pm 0.222$ & $0.123 \pm 0.016$ & $0.145 \pm 0.039$ \\
& Yes & $0.152 \pm 0.031$ & $0.156 \pm 0.019$ & $0.108 \pm 0.010$ & $0.160 \pm 0.027$ \\
Presence area 10\% & No & $0.224 \pm 0.007$ & $0.380 \pm 0.016$ & $0.208 \pm 0.004$ & $0.397 \pm 0.014$ \\
& Yes & $0.230 \pm 0.004$ & $0.415 \pm 0.013^{*}$ & $0.204 \pm 0.002$ & $0.426 \pm 0.012$ \\
OR0\% & No & $0.010 \pm 0.006$ & $0.008 \pm 0.005$ & 0 & $0.030 \pm 0.017$ \\
Pes & Yo & $0.014 \pm 0.010$ & $0.008 \pm 0.005$ & $0.014 \pm 0.003^{*}$ & $0.055 \pm 0.012$ \\
& Yes & $0.712 \pm 0.035$ & $0.946 \pm 0.005$ & $0.969 \pm 0.001$ & $0.648 \pm 0.015$ \\
& Presence area 0\% & $0.395 \pm 0.009^{*}$ & $0.869 \pm 0.013^{*}$ & $0.648 \pm 0.024^{*}$ & $0.690 \pm 0.015$ \\
\hline
\end{tabular}

*Significant difference between models with and without palms (paired $t$-test, significance level $=0.05$ )

Notes: All values correspond to mean \pm standard error (based on 10 repetitions)

Table 8 More important variables contributing to Rhodnius spp. ecological niche models

\begin{tabular}{lll}
\hline Rhodnius species & Environmental variables only & $\begin{array}{l}\text { Environmental variables and } \\
\text { palm distributions }\end{array}$ \\
\hline R. neglectus & Mean NDVI & LST annual phase \\
& NDVI annual phase & A. butyracea \\
& LST annual phase & A. aculeata \\
& Precipitation of warmest quarter & A. aculeatum \\
R. pictipes & Mean NDVI & Mean NDVI \\
& NDVI annual phase & Annual precipitation \\
& Precipitation of warmest quarter & Precipitation of warmest quarter \\
& Annual precipitation & A. phalerata \\
& Mean NDVI & Mean LST \\
R. prolixus & Mean LST & NDVI annual phase \\
& Annual mean temperature & A. maripa \\
& Annual precipitation & A. aculeata \\
& Mean NDVI & Annual mean temperature \\
& Mean LST & Annual precipitation \\
& Annual mean temperature & A. aculeatum
\end{tabular}

factor for the three Rhodnius species. In the ENMs without palms, NDVI and temperature were very important environmental factors highly contributing to the models of the four Rhodnius species.

\section{Discussion}

As for most ecological relations, general patterns could not be found for Rhodnius-palm interactions, but in terms of niche similarity, overlap was found between the genus Rhodnius and infested palms and among all Rhodnius and palm species. Almost all the environmental 
conditions suitable for Rhodnius triatomines were suitable for at least one infested palm species, while almost $40 \%$ of environmental conditions suitable for infested palms were not suitable for Rhodnius triatomines. This result could indicate that the Rhodnius niche could be somehow influenced by the palms presence, showing a possible dependence. Considering the analyses made by Rhodnius species, the association was even more noticeable, since the entire set of suitable conditions for $R$. neglectus and $R$. pictipes were also suitable for infested palms.

Palm and Rhodnius species shared, to a greater or lesser extent, environmental requirements, and the degree of niche similarity depended critically on the species involved. In the four Rhodnius species, at least one palm species shared almost all the suitable environmental conditions with the Rhodnius species (minimum overlap over $80 \%$ of the Rhodnius species niche). In most of the Rhodnius-palm interactions reported in the literature (Table 2), the overlap between niches was high (more than a half of the Rhodnius species niche). Only two reported Rhodnius-palm interactions had a relatively low niche overlap (less than $30 \%$ ) constituted by $R$. neglectus with Ac. aculeata and with $A$. phalerata. This reduced overlap can be explained as a result of the normalization process since a niche overlap could be wide in volume, but it becomes small when compared to a huge niche. That is the case with $R$. neglectus, which had the largest niche among the Rhodnius species. Additionally, the proportion of niche overlap was also affected by the palm niche volume. Palm species with the largest niches such as $M$. flexuosa, had the biggest mean niche overlap with Rhodnius species (90.11\%), while A. butyracea, with the smallest niche, had the minimum niche overlap (39.53\%). However, all seven palm species shared a great part of their environmental requirements with at least one Rhodnius species (Table 3 ).

Regarding comparisons in geographical space, most of the areas with suitable conditions for Rhodnius species were also suitable for more than one palm species in the majority of the locations (Table 4, Figs. 3 and 4). These areas corresponded geographically with zones of high richness of Rhodnius spp. and palms in northern and central South America. The genus Rhodnius has shown unimodal richness distribution strongly skewed toward the low latitudes in the Northern Hemisphere [10], while palms show a great diversification in the Andean, Amazon and Central Brazilian regions [17].

From the Rhodnius-palm interactions reported in the literature (Additional file 1: Table S1), 12 shared relatively large suitable areas (Table 5), indicating a possible relationship between Rhodnius-palm co-occurrence and palm infestation. However, two observations do not support the statement. First, some Rhodnius-palm species combinations with wide potential co-occurrence areas had no reported infestations, and secondly, $R$. pictipes and $R$. robustus infestation was reported in Ac. aculeata palms [35, 36], but the areas of potential cooccurrence were very scarce (Table 5). For the first situation, it is important to mention that the palm species involved was $M$. flexuosa, which had the most extended geographical range and the widest niche. When a palm species has a very large niche and a vast presence area, it is more likely that it will include several Rhodnius species distributions. Therefore, palm infestation by a Rhodnius species is not guaranteed to occur when the palm and the Rhodnius species share vast suitable areas; nonetheless, co-occurrence could be an initial step for a further infestation of palms by insects. Other factors intervening at a smaller spatial scale such as palm morphology and associated fauna would be the determinants for the infestation of a particular palm [37]. It is also important to mention that previous palm infestation reports are far from being systematic studies covering great range extensions, and most of them are local studies focused on small areas compared to the huge geographical extension considered in this study [6, 38-43]. Most of the geographical areas covered by these ENMs have not been sampled yet.

Almost every Rhodnius-palm niche overlap in the environmental space (Table 2) was larger than that in the geographical space (Table 5), suggesting that high niche similarity was not always associated to large areas of potential co-occurrence; the only exception was $R$. pictipes and $A$. butyracea. For example, A. aculeata shared a very high proportion of $R$. pictipes niche volume (76.63\%), but only a small proportion of suitable geographical area (9.72\%), suggesting that the spatial distribution of environmental conditions is relevant to explain co-occurrence through niche similarity.

Areas with no suitable conditions for infested palms (Figs. 3 and 4) can be interpreted as not suitable for the selected seven palm species but suitable for other infested palms not included in the study (such as A. speciosa, Cc. nucifera and $C p$. tectorum, etc.), or areas with no suitable conditions to any palm species (e.g. very elevated zones). For $R$. prolixus, no suitable areas were placed in elevated locations, along the Andean region. Rhodnius presence in zones with no predicted presence of the selected palms could be explained by infestations of different palm species or by ecological processes as domiciliation. Rhodnius prolixus in Andean locations have been observed in human dwellings [7], where insect populations can establish without the presence of palms in the proximity [44]. Rhodnius neglectus is considered as a synanthropic species that invades and sporadically colonize man-made ecotopes, and $R$. robustus and $R$. pictipes invade but do 
not colonize houses [39]. Moreover, $R$. robustus and $R$. pictipes have been found in other habitats different to palms, such as bromeliads [4].

To determine if palm presence could be a predictor of Rhodnius species distribution, Rhodnius ENMs were run with and without palm distributions as environmental variables. Performance statistics (pAUC and omission rates) were similar in both types of models. However, when palm distributions were used, they demonstrated to be relevant predictors for Rhodnius models compared to the environmental variables (Table 8). The most notorious impact of palm inclusion was the reduction of Rhodnius predicted presence area without increasing significantly the omission rates, and therefore, reducing the commission rate of the ENMs. This importance of palm distribution on Rhodnius ENMs would corroborate the spatial association between both organisms, which was also found with the niche comparison. Rhodnius presence would not be restricted to palm presence but the zones with palm presence could be more suitable for Rhodnius presence.

Association between palms and Rhodnius distribution could also be related to the fact that environmental variables such as temperature and precipitation have been shown to be important for both organisms. Triatomines and palms have shown a high sensitivity to climatic conditions. For example, temperature affects physiological and behavioral processes of triatomines such as egg production, hatching and immature development [45], and temperature and temperature seasonality have been shown to play an important role in explaining triatomine richness and distribution [46]. When considering palms, they are affected by temperature conditions due to their soft and water-rich tissues, their inability to undergo dormancy and their general lack of mechanisms to avoid or tolerate frost [47].

Although the ENMs performance was satisfactory, it is important to highlight that models are highly susceptible to the information available. The biased distribution of information (e.g. some areas intensively sampled in comparison to others) could limit the validity of the conclusions. In this study, our conclusions were based on the group of Rhodnius species and Rhodnius-infested palm species. Other cases of Rhodniuspalms reported interactions, such as $R$. ecuadoriensis in Phytelephas aequatorialis [48], R. nasutus in Copernicia prunifera [49], and $R$. pallescens in A. butyracea [50], were not considered here due to the low number of Rhodnius occurrences. It would be necessary to obtain more information about their occurrence to verify the magnitude of the patterns found in this study.

\section{Conclusions}

Niche overlap was found between the genus Rhodnius and infested palms and among all Rhodnius and palm species. As expected, the Rhodnius niche appears to be more limited by the palms niche than vice versa, showing a possible dependence of Rhodnius presence on the distribution of palms. Rhodnius and palm species shared, to a greater or lesser extent, environmental requirements depending on the species involved. Most of the areas with suitable conditions for Rhodnius species were also suitable to palm species, being favorable for more than one palm species in the majority of the locations. Lastly, even though the presence of palms was relevant for Rhodnius ENMs, their effect did not increase model's performance. This would be a consequence of the type of relationship between Rhodnius spp. and palms, where there are no clear inter-species associations and one Rhodnius species could inhabit more than one palm species.

\section{Supplementary information}

Supplementary information accompanies this paper at https://doi. org/10.1186/s13071-020-04088-0.

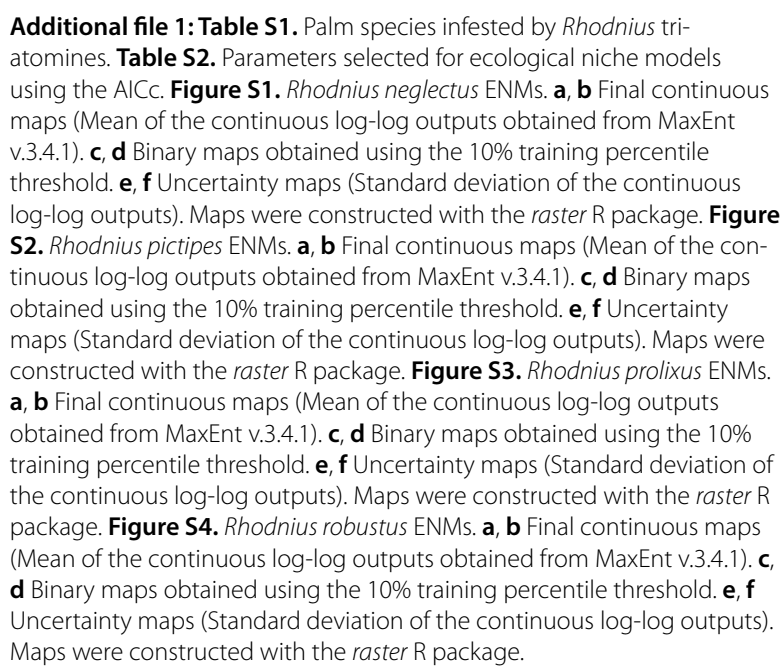

\section{Abbreviations}

ENM: ecological niche model; GBIF: Global Biodiversity Information Facility; LST: land surface temperature; NDVI: normalized difference vegetation index; MIR: middle infrared radiation; MVE: minimum-volume ellipsoids; PCA: principal components analysis; MaxEnt: maximum entropy algorithm; AICc: corrected Akaike information criterion; pAUC: partial area under the ROC curve; OR: omission rates.

\section{Acknowledgments}

We thank Juan Manuel Cordovez (Universidad de Los Andes, Colombia) and Nicole L. Gottdenker (University of Georgia, USA) for their helpful discussion and suggestions. We thank the Biological Sciences Department of the Universidad de Los Andes for allowing us the use of their facilities and their technical support. 


\section{Authors' contributions}

JMC and CG conceived the study, JMC collected and analyzed the data, and JMC and CG wrote the manuscript. Both authors read and approved the final manuscript.

\section{Authors' information}

Johan Calderón is a Doctoral student in the Universidad de Los Andes in Bogotá, Colombia. He works in disease ecology of infectious diseases, spatial epidemiology and species ecological interactions. Camila González is an associate professor in the Universidad de Los Andes, Colombia. She is interested in disease ecology, spatial analysis and ecological models of zoonotic transmission.

\section{Funding}

This study was funded by Colciencias call 647

\section{Availability of data and materials}

Data supporting the conclusions of this article are included within the article and its additional files. The datasets generated and analyzed during the present study are available from the corresponding author upon reasonable request.

\section{Ethics approval and consent to participate} Not applicable.

\section{Consent for publication}

Not applicable.

\section{Competing interests}

The authors declare that they have no competing interest.

Received: 25 October 2019 Accepted: 15 April 2020

Published online: 22 April 2020

\section{References}

1. WHO. Chagas disease (American trypanosomiasis) fact sheet (revised in June 2010). Wkly Epidemiol Rec. 2010;85:334-6.

2. Gaunt M, Miles M. The ecotopes and evolution of triatomine bugs (Triatominae) and their associated trypanosomes. Mem Inst Oswaldo Cruz. 2000;95:557-65.

3. Galvão C, Justi SA. An overview on the ecology of Triatominae (Hemiptera: Reduviidae). Acta Trop. 2015;151:116-25.

4. Lent H, Wygodzinsky P. Revision of the Triatominae (Hemiptera, Reduviidae), and their significance as vectors of Chagas' disease. Bull Am Museum Nat Hist. 1979;163:123-520.

5. Abad-Franch F, Lima MM, Sarquis O, Gurgel-Gonçalves R, Sánchez-Martín M, Calzada J, et al. On palms, bugs, and Chagas disease in the Americas. Acta Trop. 2015;151:126-41.

6. Dias FBS, Bezerra CM, De Menezes Machado EM, Casanova C, Diotaiuti L. Ecological aspects of Rhodnius nasutus Stål, 1859 (Hemiptera: Reduviidae: Triatominae) in palms of the Chapada do Araripe in Ceará, Brazil. Mem Inst Oswaldo Cruz. 2008;103:824-30

7. Fitzpatrick S, Feliciangeli MD, Sanchez-Martin MJ, Monteiro FA, Miles MA Molecular genetics reveal that silvatic Rhodnius prolixus do colonise rural houses. PLoS Negl Trop Dis. 2008;2:e210.

8. Sanchez-Martin MJ, Feliciangeli MD, Campbell-Lendrum D, Davies CR. Could the Chagas disease elimination programme in Venezuela be compromised by reinvasion of houses by sylvatic Rhodnius prolixus bug populations? Trop Med Int Health. 2006;11:1585-93.

9. Galeano G, Bernal R. Palmas de Colombia. Guía de campo. Bogotá D.C.: Editorial Universidad Nacional de Colombia; 2010.

10. Gorla D, Noireau F. Geographic distribution of Triatominae vectors in America. In: Telleria J, Tibayrenc M, editors. American trypanosomiasis Chagas disease. One hundred years of research. 2nd ed. Amsterdam: Elsevier; 2017. p. 197-222.

11. Carcavallo RU, Curto de Casas SI, Sherlock ÍA, Galíndez Girón I, Jurberg J, Galvao C, et al. Geographical distribution and alti-latitudinal dispersion. In: Carcavallo RU, Galíndez Girón I, Jurberg J, Lent H, editors. Atlas of Chagas disease vectors in the Americas. Rio de Janeiro: Fiocruz; 1999. p. 747-92.
12. James FC, Johnston RF, Wamer NO, Niemi GJ, Boecklen WJ. The Grinnellian niche of the wood thrush. Am Nat. 1984;124:17-47.

13. Franklin J. Mapping species distribution. Cambridge: Cambridge University Press; 2009

14. Peterson AT, Soberón J, Pearson RG, Anderson RP, Martínez-Meyer E, Nakamura $M$, et al. Ecological niches and geographic distributions. Princeton: Princeton University Press; 2011.

15. Ceccarelli S, Balsalobre A, Medone P, Cano ME, Gonçalves RG, Feliciangeli D, et al. Data descriptor: DataTri, a database of American triatomine species occurrence. Sci Data. 2018;5:180071.

16. Hijmans RJ, Phillips S, Leathwick J, Elith J. dismo: species distribution modeling. R package version 1.1-4. 2017.

17. Henderson A, Galeano G, Bernal R. Field guide to the palm of the Americas. Princeton: Princeton University Press; 1995.

18. Molina J, Gualdrón LE, Brochero HL, Olano V, Barrios D, Guhl F, et al. Distribución actual e importancia epidemiológica de las especies de triatominos (Reduviidae: Triatominae) en Colombia. Biomédica. 2000;20:344-60.

19. Aguilar HM, Abad-Franch F, Dias JCP, Junqueira ACV, Coura JR. Chagas disease in the Amazon region. Mem Inst Oswaldo Cruz. 2007;102(Suppl. 1):47-56.

20. Gurgel-Goncalves R, Cuba CAC. Predicting the potential geographical distribution of Rhodnius neglectus (Hemiptera, Reduviidae) based on ecological niche modeling. J Med Entomol. 2009;46:952-60.

21. Hashimoto K, Schofield CJ. Elimination of Rhodnius prolixus in Central America. Parasite. 2012:5:45.

22. Aiello-Lammens ME, Boria RA, Radosavljevic A, Vilela B, Anderson RP. spThin: an $\mathrm{R}$ package for spatial thinning of species occurrence records for use in ecological niche models. Ecography. 2015;38:541-5.

23. Pearson RG, Raxworthy CJ, Nakamura M, Peterson AT. Predicting species distributions from small numbers of occurrence records: a test case using cryptic geckos in Madagascar. J Biogeogr. 2007;34:102-17.

24. Anderson RP, Raza A. The effect of the extent of the study region on GIS models of species geographic distributions and estimates of niche evolution: preliminary tests with montane rodents (genus Nephelomys) in Venezuela. J Biogeogr. 2010;37:1378-93.

25. Jácome-Pinilla D, Hincapie-Peñaloza E, Ortiz MI, Ramírez JD, Guhl F, Molina J. Risks associated with dispersive nocturnal flights of sylvatic Triatominae to artificial lights in a model house in the northeastern plains of Colombia. Parasit Vectors. 2015;8:600

26. Hijmans RJ, Cameron SE, Parra JL, Jones PG, Jarvis A. Very high resolution interpolated climate surfaces for global land areas. Int J Climatol. 2005:25:1965-78.

27. Hay SI, Tatem AJ, Graham AJ, Goetz SJ, Rogers DJ. Global environmental data for mapping infectious disease distribution. Adv Parasitol. 2006;62:37-77.

28. Guisan A, Thuiller W, Zimmermann NE. Habitat suitability and distribution models. With applications in R. Cambridge: Cambridge University Press; 2017

29. Qiao H, Peterson AT, Campbell LP, Soberón J, Ji L, Escobar LE. NicheA: creating virtual species and ecological niches in multivariate environmental scenarios. Ecography. 2016;39:805-13.

30. Phillips SB, Anderson RP, Schapire RE. Maximum entropy modeling of species geographic distributions. Ecol Modell. 2006;190:231-59.

31. Anderson RP. When and how should biotic interactions be considered in models of species niches and distributions? J Biogeogr. 2017;44:8-17.

32. Soberón J, Peterson AT. What is the shape of the fundamental Grinnellian niche? Theor Ecol. 2020;13:105-15.

33. Muscarella R, Galante PJ, Soley-Guardia M, Boria RA, Kass JM, Uriarte M, et al. ENMeval: an R package for conducting spatially independent evaluations and estimating optimal model complexity for Maxent ecological niche models. Methods Ecol Evol. 2014:5:1198-205.

34. Peterson AT, Papeş M, Soberón J. Rethinking receiver operating characteristic analysis applications in ecological niche modeling. Ecol Modell. 2008;213:63-72

35. Ricardo-Silva AH, Lopes CM, Ramos LB, Marques WA, Mello CB, Duarte R, et al. Correlation between populations of Rhodnius and presence of palm trees as risk factors for the emergence of Chagas disease in Amazon region, Brazil. Acta Trop. 2012;123:217-23.

36. Longa A, Scorza JV. Migración de Rhodnius robustus (Hemiptera: Triatominae) desde Acrocomia aculeata (Palmae) hacia domicilios rurales en Venezuela. Bol Malariol Salud Ambient. 2007;47:213-20. 
37. Abad-Franch F, Ferraz G, Campos C, Palomeque FS, Grijalva MJ, Aguilar HM, et al. Modeling disease vector occurrence when detection is imperfect: infestation of Amazonian palm trees by triatomine bugs at three spatial scales. PLoS Negl Trop Dis. 2010;4:e620.

38. Noireau F, Abad-Franch F, Valente SAS, Dias-Lima A, Lopes CM, Cunha V, et al. Trapping triatominae in silvatic habitats. Mem Inst Oswaldo Cruz. 2002;97:61-3.

39. Abad-Franch F, Monteiro FA, Jaramillo ON, Gurgel-Gonçalves R, Dias FBS, Diotaiuti L. Ecology, evolution, and the long-term surveillance of vector-borne Chagas disease: a multi-scale appraisal of the tribe Rhodniini (Triatominae). Acta Trop. 2009;110:159-77.

40. Gurgel-Gonçalves R, Cuba CAC. Estrutura de populações de Rhodnius neglectus Lent e Psammolestes tertius Lent \& Jurberg (Hemiptera, Reduviidae) em ninhos de pássaros (Furnariidae) presentes na palmeira Mauritia flexuosa no Distrito Federal, Brasil. Rev Bras Zool. 2007;24:157-63.

41. Pizarro Novoa JC, Romaña C. Variación estacional de una población silvestre de Rhodnius pallescens Barber 1932 (Heteroptera: Triatomiane) en la costa caribe colombiana. Bull Inst Fr Études Andin. 1998;27:309-25.

42. Angulo VM, Esteban L, Luna KP. Attalea butyracea próximas a las viviendas como posible fuente de infestación domiciliaria por Rhodnius prolixus (Hemiptera: Reduviidae) en los Llanos Orientales de Colombia. Biomédica. 2012;32:277-85

43. D'Alessandro A, Barreto P, Saravia N, Barreto M. Epidemiology of Trypanosoma cruzi in the oriental plains of Colombia. Am J Trop Med Hyg. 1984;33:1084-95.
44. Catalá SS, Noireau F, Dujardin JP. Biology of Triatominae. In: Telleria J, Tibayrenc M, editors. American trypanosomiasis Chagas disease. One hundred years of research. 2nd ed. Amsterdam: Elsevier; 2017. p. 145-68.

45. Luz C, Fargues J, Grunewald J. Development of Rhodnius prolixus (Hemiptera: Reduviidae) under constant and cyclic conditions of temperature and humidity. Mem Inst Oswaldo Cruz. 1999;94:403-9.

46. Diniz-Filho JAF, Ceccarelli S, Hasperué W, Rabinovich J. Geographical patterns of Triatominae (Heteroptera: Reduviidae) richness and distribution in the Western Hemisphere. Insect Conserv Divers. 2013;6:704-14.

47. Tomlinson PB. The uniqueness of palms. Bot I Linn Soc. 2006;151:5-14.

48. Abad-Franch F, Palomeque FS, Aguilar VHM, Miles MA. Field ecology of sylvatic Rhodnius populations (Heteroptera, Triatominae): risk factors for palm tree infestation in western Ecuador. Trop Med Int Health. 2005;10:1258-66.

49. Dias FBS, de Paula AS, Belisário CJ, Lorenzo MG, Bezerra CM, Harry M, et al. Influence of the palm tree species on the variability of Rhodnius nasutus Stål, 1859 (Hemiptera, Reduviidae, Triatominae). Infect Genet Evol. 2011;11:869-77.

50. Gottdenker NL, Calzada JE, Saldaña A, Carroll CR. Association of anthropogenic land use change and increased abundance of the Chagas disease vector Rhodnius pallescens in a rural landscape of Panama. Am J Trop Med Hyg. 2011;84:70-7.

\section{Publisher's Note}

Springer Nature remains neutral with regard to jurisdictional claims in published maps and institutional affiliations. 